\title{
Establishing Health Mentals on the Use of Number Sense on Operations with Integers
}

\author{
Sumaji Sumaji ${ }^{1 *}$, Akbar Sutowijaya $^{2}$, Subanji Subanji ${ }^{2}$, Tjang Daniel Chandra $^{2}$ \\ ${ }^{1}$ Department of Education, Faculty of Education, Universitas Muhammadiyah Ponorogo, Ponorogo, Indonesia; ${ }^{2}$ Department of \\ Education, Faculty of Education, Universitas Negeri Malang, Malang, Indonesia
}

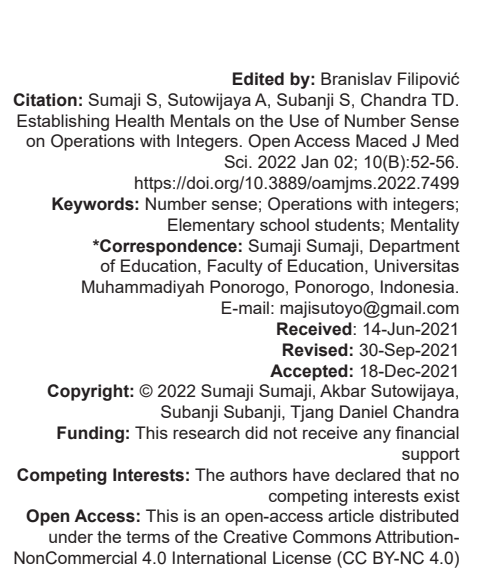

\section{Introduction}

In this global era, an excellent mental health is needed. Digital activites across interdisciplinary cannot be avoided. In this era, many children experience mental health disorders. Many children are stressed because they are not mentally ready for the dynamic changes. Someone who is mentally healthy can use his abilities or potential to the fullest in facing life's challenges, as well as establishing positive relationships with other people. According to the World Health Organization (WHO) as stated by Halida, mental health is a state of well-being in which individuals are able to: Realize their abilities, cope with pressures and stress in daily life, work productively, and are able to contribute actively in their environment or community [1].

Technological developments are increasingly rapid and fast. It requires a good mental health to control social life. Number sense in mathematics is one of ways to build resilience. Number sense is numeration using mental, so with number sense there will be verbalization of reasoning. Verbalizing their reasoning helps students to develop their critical thinking and express the idea. Children will have a good mental health by having practical strategies for building mental resilience from early age.

The basis of mathematics is counting. For this reason, counting skill is highly emphasized in learning mathematics in elementary school. The usefulness of numeracy in the development of other sciences, in a material sense, seems not so meaningful, but in the development of reasoning and mental health, namely, formal goals, it is much beneficial. In primary education, learning mathematics or arithmetic consists of four principles: Addition, subtraction, multiplication, and division. In Javanese, in ancient times, this arithmetic was called pipolondo. As a science, the existence of arithmetic continues to grow. Its development in Indonesia cannot be separated from the results of the latest overseas studies [1].

We need to be able to calculate accurately and efficiently. Now, there are many calculators and the proliferation of "Mental Arithmetic," making it very easy to calculate. However, it is only a skill. As an educator, you will certainly be more interested in the theory of learning which correlates with mental health. Learning mathematics (for elementary school children), we try to compare counting and addition using algorithms and number sense. Number sense is not a method of 
counting. It refers to a group of key math abilities (the word sense has played an important role since primary school). As we may often hear "A has a good sense of humor," it means that people who have a good sense of humor have mental sensitivity and skills to perceive humor or appreciate a joke. People who have a good sense of humor do not need many and complicated words to make jokes, with one simple word that he says can make a good joke. Likewise, the sense of number is analogous to that sense of humor. One who has a good sense of numbers is expected to have the skills and mental sensitivity to process numbers so that it can make it easier to count [2].

Number sense is a skill. If it is properly trained or developed, it will be beneficial for students. Number sense is very good for supporting mental and logical intelligence especially in mathematics, particularly numbers [1]. Students who often practicing number sense questions correctly will make creative in solving math problems [2]. This statement is under the result of a previous study conducted by Yang and Hsu [3] that number sense refers to an individual's general understanding of numbers and their operations, with the ability to develop usefully mentally. It is flexible and efficient strategies for handling numerical problems.

Fosnot [4] states that students who have good number sense skills indirectly have a flexible and confident nature and can overcome various kinds of questions related to numbers and can apply them in real-life experience. It is further explained that the mental ability of number sense can be trained for every child. A child is not born with the ability to number sense, but educators must explore the child's number sense. By exploring students' number sense abilities, educators can determine the development of students' thinking, strategies used, and misconceptions. The benefits of understanding number sense are the student had a very healthy mind that students can: 1) Know relative values, 2) use it to make judgments, 3) use it flexibly when adding, subtracting, multiplying, or dividing, and 4) develop useful strategies when calculating, measuring, or estimating.

The following experts provide opinions described in Saleh's book [5].

(1) Fennel and Landis define "Number sense as is one of a person's awareness and understanding of numbers, the relationship between numbers, their importance, and calculations using his mental ability."

Burton and Reys stated that "Number sense is a person's perspective on a number and its calculation. People with good and superior mental use various methods and strategies to solve complex problems."

(3) Howden argues that "Number sense is an exploration of numbers, putting them in a problem, and connecting the two without being limited by old-fashioned algorithms."
(4)

Gersten and Chard argue that "Number sense is the freedom and feelings of children toward a number. This can boost the ability to develop mentally.

(5) Bobis defines "Number sense is an organized concept of a number."

(6) Tsao and Lin [6] define number sense as follows: "Number sense refers to a person's general understanding and their operations accompanied by the mental ability and tendency to use this understanding in flexible ways to make judgments and to develop efficient use and strategies for manage numerical or nonnumerical situations."

There is general agreement among researchers that if students' number sense skills are developed properly, they could have a good and healthy mentality to find solutions to the problems they face. In addition, according to the As'ari [7], people who have good number sense tend to have great confidence in their mental and mind.

The key elements of building mental health and ability are the usage of number sense in students, including the ability to think with small numbers, distinguish between number processing, calculate, compare quantities, and perform simple number transformations. Based on the explanation of the definition of number sense above, it can be concluded that the ability of number sense is the ability of students to solve questions related to numbers using calculation interpretations without using mathematical algorithms. In other words, with good number sense, students will be easy, flexible, and confident to overcome various kinds of problems. The impact is not only learning numbers but also, they will have the confidence to learn another field.

There are two models of number sense dimensions, namely, basic skills and conventional arithmetic. Jordan et al. [8] describe that the dimensions of basic abilities include counting, recognizing numbers, knowing numbers, non-verbal calculations, estimations, and number patterns. Another dimension, the conventional arithmetic, includes number combinations and story problems. An important aspect of number sense stated by Jordan et al. is summarized in five key elements of children's health mental indication with number sense [8]. Those are described as follows:

- Counting skills: Knowing one-to-one correspondence, stable sequences, knowledge of the cardinality principle, and knowing arithmetic sequences.

- Knowledge of numbers: Describe and coordinate quantities and make comparisons of numbers.

- Math transformation: The transformation of numbers with addition, subtraction, calculations in verbal and non-verbal contexts, and calculations with or without assistance (physical or verbal). 
Estimation: Estimate the size of the set and use point references.

- Numerical patterns: Imitate number patterns, enlarge number patterns, and see the relationship between numbers.

The student's ability profile is a natural picture of students' skills, abilities, and capacities in completing their assigned tasks. According to the researcher, students' mentalities refer to a description of their ability to solve problems, especially in math. The mentals' ability to solve the problem discussed is the integers in math for primary school Grade VI. The skills studied include:

1. Having sensitivity to sort integers. Students with this ability can:

- Recognize the "sequential" nature of numbers and the regularity of the integer system, that is, sorting integers from smallest to largest or vice versa - $\quad$ Define integer relation algorithm.

2. Identifying the sensitivity to the knowledge of numbers

- Describe an integer.

- Represent an integer to another integer (comparing greater, lesser, or equal).

3. Identifying proficiency and mastery of number transformations that refers to understanding operations and their effects on integers which include:

- $\quad$ Add integers.

- Subtract integers.

- Multiply integers.

- $\quad$ Divide integers.

- Recognize the types of operations, their relationships, and can apply these relationships.

- $\quad$ Determine the relationship between numbers (determining which number

4. Estimation is greater, lesser, or equal to).

- Determine whether the known number is more or less to get the right answer.

- $\quad$ Determine whether the answer given is more or less than the reference numbers given.

5. Numerical Patterns

- Solve problems with numerical or patterns accurately.

\section{Methods}

The study was qualitative descriptive research. According to the Nawawi [9], the descriptive method can be reported as a problem-solving procedure that is investigated by describing the state of the subject or object of research at present based on the facts that appear as they are. This qualitative research was a case study. According to the Arikunto [10], case study research is an intensive, detailed, and in-depth study of an organism, institution, or particular phenomenon.

The subjects in this study were students of Class VI Sekolah Dasar Muhammadiyah Terpadu (SDMT) Ponorogo. There were two classes for Grade VI, the Sidiq class and the Amanah class. From those two classes, one class was selected, namely, the Sidiq class with a total of 23 students. It was considered that the Sidiq class had a higher concern for mental learning, especially than the Amanah class. The research procedure consisted of three stages: 1) Preliminary stage processed a consideration from review board to conduct a research 2) collecting data stage, and 3 ) the final stage.

Preliminary stage activities include: (1) Conducting pre-research at the targeted school by interviewing the mathematics teacher who teaches at the school, (2) compiling research indicators in the form of a grid of questions, number sense test questions, answer keys, and clinical interview guidelines.

After collecting the data, it was interpreted according to the literature review. These included (1) giving number sense test questions to 23 Sidiq class students and (2) interviewing several students who have thought processes under the number sense indicator of 23 students who took the number sense test to support students' answers.

The researcher carried out these steps to report the data: (1) Describing research data analysis and reporting research findings based on research questions proposed.

Instruments used for data collection were tests and interviews. The test was a written test (research question). It was described in the form of an essay and equipped with interview guidelines. The research questions were made up of five questions. Interviews are a supporting tool in finding the number sense ability profile of sixth-grade elementary school students in solving integer arithmetic operations. According to the Nawawi [9], the interview is an attempt to collect information by asking several oral questions that propose to answer orally as well. The type of interview used is a clinical interview. The purpose of using clinical interviews is to find a student's number sense profile in solving integer arithmetic operations. The subjects of the study were 23 students of the Grade VII Sidiq class.

\section{Results}

Ordering numbers in everyday life are a basic competence. If the ability to sort numbers is weak, he will experience a lot of anxiety, anxiety which eventually disrupts his mental health. The World Health Organization states that mental health is a state of 
well-being that is realized by individuals, in which there are abilities to manage normal life stressors, to work productively and productively, and to participate in their communities (Table 1).

Table 1: Number sense of students

\begin{tabular}{llll}
\hline S. No. & Number Sense & Number of students & Percentage \\
\hline 1. & Number Sort & 12 & 52.2 \\
2. & Numerical Knowledge & 7 & 30.5 \\
3. & Transformation Skill & 5 & 21.7 \\
4. & Estimation Skill & 15 & 65.5 \\
5 & Numerical Pattern & 12 & 52.2 \\
\hline
\end{tabular}

\section{Discussion}

According to the answers of Class VI students of SDMT Ponorogo, it was figured out that the number sense of each student was different. Although they were very familiar with the test, the ability to solve integer operations seems still low in the number sense. Some students had skills to count but did not necessarily have the ability to know numbers, transformation knowledge, estimation, or making patterns. Likewise, students who had the ability in number knowledge did not necessarily have the ability in other number sense indicators.

\section{Number sort skill}

There were 12 of 23 students who were able to sort integers; for example, MFA, YWA, NST, RDR, AFN, AND, PMI, YDM, TYS, PRD, UAH, and PTM. After conducting in-depth interviews, students found it difficult to distinguish between a sequence of small and large negative numbers. From question number 1 , students experienced a lot of ordering errors $-11,-100$, and -1000 . They assume that -1000 was $>-100$ and -11 , thus -100 was $>-11$. Hence, the results of sorting the numbers from smallest to largest in problem number 1 lot were as follows: $-11,-100,-1000,999,1001$, 1029, and 1111.

Ordering numbers in everyday life is a basic competence. If the ability to sort numbers is weak, he will experience a lot of anxiety, anxiety which eventually disrupts his mental health. The WHO (2001) states that mental health is a state of well-being that is realized by individuals, in which, there are abilities to manage normal life stressors, to work productively and productively, and to participate in their communities.

\section{Numerical knowledge}

Based on the results of the research, there were two numerical knowledge descriptions. First, it was the ability to know numbers the ability to describe a number. Second, it was numerical representation including comparing a number. It was found that there were only seven students who answered correctly,
RDR, ARF, RAS, AND, PMI, YDM, and PTM. The most of the students were less able to form a number formed from two numbers whose value was greater, less than, and equal to. Being interviewed, it was reported that many students found it difficult to add and subtract negative numbers. In question number 2 , it was provided numbers; $-15,5,20,-20,-5$, and -10 , in the form of addition or subtraction of two or more numbers. Therefore, the value was greater, less than, and equal to the other two or more numbers. Most students were confused in representing the numbers formed.

This makes students feel insecure and inferior. It will bother their relationship with his friends. Whereas in education, students must be able to interact with friends and their environment well. Pieper and Uden (2006) stated that mental health is a condition in which a person does not experience feelings of guilt about himself. In addition, he also has a realistic estimate of himself and can accept his shortcomings and weaknesses, having the ability to face problems in his life and satisfaction in his social life.

\section{Transformation skill}

Students were familiar with integers. However, they found it difficult when used multiple methods to solve it. Based on the results of the study, only five students were able to complete using number sense correctly: ARF, AFN, AND, YDM, and PRD. After having in-depth interviews, it was reported that they had never been given open-ended questions. They were given training every day. As in question number 3 , describing $1196+2394$, they only work through one method. The trick was stacking. There were three students who worked with $1200+2390=3590$. Moreover, there were two students who answered $1190+2400=3590$.

Life in society cannot always be solved in one way. Problem solving in society demands creativity. Namber sense will train students to think quickly, accurately, and creatively, so that every problem they face can be solved properly. Life ahead will be calm and mental success will be formed. Someone who is mentally healthy can use his abilities or potential to the fullest in facing life's challenges, as well as establishing positive relationships with other people.

\section{Estimation skill}

Estimation is significantly necessary for reallife experience. It cannot be separated from our daily routines that estimation is used for shopping. Based on the results, it was found that there were 15 of 23 students who were able to answer question number 4 correctly. However, one student and another had a different method to solve. Those students were MFA, RDR, ARF, AFM, AND, ALN, DN, PMI, YDM, MBHD, IAR, BFA, YSF, TYS, and PRD. 
About $80 \%$ of people living in society use estimate-competence. Learning number sense mathematics will train mentally in estimation. Therefore, by learning number sense, students will mentally calm and quickly adapt in the circumstances easily. The $\mathrm{WHO}$ also clarifies this by mentioning four main criteria for a person to be declared mentally healthy, namely, recognizing one's potential, being able to cope with daily stress, being productive, and being useful to others.

\section{Numerical pattern skill}

The numerical pattern has a significant role in the mathematical thinking process. How one solves math problems, particularly in the academic potential test, is necessary to analyze and develop the pattern. Based on the research results, 12 of 23 SDMT students worked on question number 5 using number sense correctly.

Those were YWA, NST, AFN, RAS, AFM, ALN, DN, PMI, YDM, YSF, UAH, and PTM. From a depthinterview, it was verified that those 12 students thought the questions would be not difficult. Therefore, they analyzed and found numerical patterns to solve the problem. Other 11 students perceived that algorithm was the best method as they previously learned and were afraid of making mistakes by finding another number sense skill.

Being mentally healthy is being mentally ready to change by leaps and bounds according to the demands of the times. The leaps in life are in accordance with the patterns developed in mental number sense. If students have been trained with number sense patterns, students are protected from anxiety disorders and depression because they have built their resilience.

\section{Conclusion}

Based on the results and discussion above, the indication of mental health of students correlated with number sense ability in solving integer operations questions for elementary school students is: Numeracy ability $52.2 \%$. It was due to the lack of emphasis on the order of numbers in the learning process. The knowledge ability is $30.5 \%$. The lack of open-ended questions in the learning process was found to lead the percentage of knowledge. It was clarified that the ability to transform numbers was $21.7 \%$. Although the operations of addition, subtraction, multiplication, and division were introduced early, but primary school students' mental's ability to solve problems approximate and estimate was $65.5 \%$. This number sense on operations with integers was based on the fact that the ability especially mental health ability is significantly necessary for everyday life.

Based on the results and discussion above, the ability of students' number sense in solving integer operation problems for elementary school students is: Numeracy skills, ability to number knowledge, ability to transform numbers, ability to estimate, and ability to make patterns so that students' mental health will be realized.

\section{References}

1. Halida A. Psikolog-Klinik Psikologi. Indonesia: RS Jiwa Grhasia DIY; 2020.

2. Pieper J, Uden MV. Religion in Coping and Mental Health Care. New York: Yord University Press; 2006.

3. Yang DC, Hsu CJ. Teaching number sense for $6^{\text {th }}$ graders in Taiwan. Int Electron J Math Educ. 2009;4(2):92-109. Available from: http://www.iejme.com/022009/d3.pdf [Last accessed on 2014 Sep 30].

4. Fosnot CT. Young Mathematics at Substruction Work: Constructing Number Sense, Addition, and Subtraction, United States of America; 2001

5. Saleh A. Number Sense, Belajar Matematika Selezat Cokelat (Number Sense, Studying Math is as Yummy as Chocolate) Bandung: Trans Media Pustaka; 2009.

6. Tsao Y, Lin Y. The Study of Number Sense and Teaching Practice. Taiwan: Journal of Case Studies in Education; 2001.

7. As'ari AR. Number Sense: Mengapa Penting bagi Anak (Number Sense, Why it is Important for Children). Ide Pembelajaran Matematika; 2008. Available from: http://www. idepembelajaranmatematika.blogspot.com/2008/11/numbersensemengapa-penting-bagi-anak.html [Last accessed on 2021 May 12].

8. Jordan NC, Kaplan D, Olah AN, Locuniak MN. Number sense growth in kindergarten: A longitudinal investigation of children at risk for mathematics difficulties. J Res dev. 2006;15:134-46.

9. Nawawi H. Metode Penelitian Bidang Sosial (Research Method in the Social Field). Yogyakarta: Gajah Mada University Press; 2012.

10. Arikunto S. Research Procedure A Practical Approach. Jakarta: Rineka Cipta; 1998. 